OPEN ACCESS

Edited by:

Andrew James Jonathan

Maclntosh,

Kyoto University, Japan

Reviewed by:

Susan Jane Cunningham,

University of Cape Town, South Africa

Claus Bech,

Norwegian University of Science

and Technology, Norway

*Correspondence:

Fredrik Andreasson

fredrik.andreasson@biol.lu.se

Specialty section:

This article was submitted to

Behavioral and Evolutionary Ecology,

a section of the journal

Frontiers in Ecology and Evolution

Received: 25 June 2020

Accepted: 17 September 2020

Published: 08 October 2020

Citation:

Andreasson F, Nilsson J-Å and Nord A (2020) Avian Reproduction

in a Warming World.

Front. Ecol. Evol. 8:576331.

doi: 10.3389/fevo.2020.576331

\section{Avian Reproduction in a Warming World}

\author{
Fredrik Andreasson*, Jan-Åke Nilsson and Andreas Nord \\ Section for Evolutionary Ecology, Department of Biology, Lund University, Lund, Sweden
}

Weather influences both the distribution and life-history strategies of birds. Temperature ranks amongst the more important weather parameters in this regard since warming springs in temperate and high latitudes and more frequent heat-waves globally have caused major changes in breeding phenology and negatively affected adult and juvenile survival, respectively. Both long-term and stochastic changes in temperature can have fundamental consequences for avian reproduction even when the effects are not lethal, such as via thermal constraints on parental provisioning and chick growth. To date, most of what we know about temperature effects on nestling development and parental effort during reproduction is based on correlative data. In addition, an increasing amount of evidence indicates that temperature change also significantly affects birds that breed in cooler temperate areas, which so far has been somewhat overlooked. Therefore, in this perspective piece, we outline the existing literature on temperature effects on nestling development and parental behavior, with an emphasis on what needs to be done to address the causal effects of temperature change on avian reproduction under climate change. We finish by providing an outlook over future avenues of research, and give suggestions of some specific areas that might be especially promising in developing this field of research.

Keywords: body temperature, climate change, life history, heterothermy, hyperthermia, overheating, reproduction, trade-off

\section{INTRODUCTION}

Weather and climate have profound effects on the distribution, reproduction, survival and behavior of birds. Two well-known examples are earlier egg laying to track warming springs and increased mortality under extreme weather events. Warmer spring temperatures in temperate and high latitudes have induced phenological shifts to synchronize the start of reproduction with earlier leafing and flowering of plants and the consequently advanced peak of caterpillar abundance (Crick et al., 1997; Visser et al., 1998; Dunn and Winkler, 1999; Sanz, 2002; Charmantier et al., 2008; Källander et al., 2017). Extreme weather events, such as heat waves, occur with increasing frequency around the globe and are predicted to continue to do so (Coumou and Robinson, 2013; Mutiibwa et al., 2015). This has been implicated as a cause of mass mortality events in several taxa, including birds (McKechnie et al., 2012; Fey et al., 2015), and has been suggested to be the driver of the collapse of entire bird communities (Riddell et al., 2019).

All temperature effects are not as apparent and dramatic, but can still influence physiology and behavior with downstream consequences for life-history decisions. Because birds are endothermic 
and largely homeothermic, they use a suite of behavioral and physiological responses to avoid overheating when air temperature increases. The risk of overheating can be reduced by seeking shade, resting, and drooping the wings (e.g., Smit et al., 2016; Pattinson et al., 2020), which lowers both heat gain and production. When air temperature increases above body temperature, the bird can only lose heat by evaporative cooling. Birds from some orders, such as nightjars and doves, have a substantial evaporative cooling capacity via both cutaneous and respiratory pathways (Smith et al., 2015; McKechnie et al., 2016; O’Connor et al., 2017; Talbot et al., 2017). Other groups, such as songbirds, rely largely on respiratory heat loss through panting, which is less effective and also involves physical work that increases heat production (Whitfield et al., 2015; McKechnie et al., 2017; Smith et al., 2017). Some of the water- and energy costs of high temperatures can be mitigated by a controlled increase in body temperature, "facultative hyperthermia” (e.g., Nilsson et al., 2016; Gerson et al., 2019). This reduces the need for heat dissipation by reducing the thermal gradient between the body and the surroundings, meaning less energy and water is needed to fuel evaporation. While these responses mostly allow the bird to avoid overheating, they are connected to other costs. For example, sustained periods of above-normal body temperature are damaging for cell membranes and may cause oxidative stress (Lin et al., 2006; Daniel et al., 2010; Del Vesco et al., 2015). Moreover, time and energy that is devoted to keeping cool must be procured from other competing demands. It follows that increased investment in thermoregulation could reduce time for other parts of self-maintenance or reproduction in adults, and draw resources away from growth in developing nestlings. Thus, even sub-lethal effects of high temperature are expected to cause population declines through constraints on foraging behavior (Conradie et al., 2019), and higher-than-normal temperature during embryonic or chick development can alter nestling physiology for the duration of the birds' life (reviewed in Nord and Giroud, 2020).

Much of what we know about the adverse effects of high temperature is derived from studies on birds in already hot and dry climates, where additional thermoregulatory challenges to an already challenging life brings effects ranging from devastating to unbearable (McKechnie and Wolf, 2010; Conradie et al., 2019, 2020; Riddell et al., 2019). However, this work is largely correlative, which complicates interpretation of the causal role of changing air temperature in explaining the observed effects. By comparison, we still know relatively little about how increasing temperature and heat waves affect physiology and behavior in adults and chicks in cooler parts of the world. Slight increases in temperature in such biomes could prove beneficial in situations where chick growth is thermally constrained (see below). On the other hand, it is also conceivable that heat waves could have serious consequences since there has likely been, at most, weak selection for heat dissipation and tolerance in temperate regions. Hence, it is clear that we have yet to understand many aspects of the causal effects of air temperature on nestling development and parental effort.
In this perspective paper, we outline the available evidence for heat wave- and temperature change effects and discuss these findings in light of ongoing climate change. We will emphasize that experimental studies are currently in high demand if we are to understand the causality of how future thermal challenges may alter breeding investment and, hence, the trade-off between current and future reproduction. We finish by outlining a number of research trajectories that we believe are the most urgent to address in future work. We will focus on studies on wild birds since those are more likely to be immediately affected by climate change compared to production animals inside temperature-controlled facilities (but see e.g., Naga Raja Kumari and Narendra Nath, 2018). Furthermore, analogous effects in poultry are covered in detail elsewhere (Yahav, 2009; Loyau et al., 2015; Nord and Giroud, 2020).

\section{EFFECTS OF NATURAL VARIATION IN TEMPERATURE ON NESTLINGS}

There is substantial variation in the reported effects of temperature on nestling growth and thermoregulation. Much of this variation can probably be explained by geographical location. For example, high air temperatures in already warm and arid parts of the world negatively influence body mass (Murphy, 1985; Cunningham et al., 2013; Salaberria et al., 2014), structural size (Cunningham et al., 2013; Salaberria et al., 2014), nestling mortality (Murphy, 1985), fledging success (Cunningham et al., 2013), and post-fledging survival (Greño et al., 2008). In contrast, high air temperatures in cooler temperate areas can have positive impact on nestling growth (McCarty and Winkler, 1999; Eeva et al., 2002). Other studies have found that nestling growth benefits from stable nest temperatures, but that variable or too high nest temperatures adversely affects growth (Lloyd and Martin, 2004; Larson et al., 2015) and fledging success (Ardia, 2013; Larson et al., 2015). However, air or nest temperature alone is probably inherently correlated with variation in food availability and, hence, parental effort. Although path analysis may aid in separation of direct and indirect effects of temperature (see McCarty and Winkler, 1999; van de Ven et al., 2020) we still need studies that experimentally manipulate nest temperature to unambiguously evaluate the causal role of increasing temperature from environmentally driven effects on parental effort and provisioning.

\section{EFFECTS OF MANIPULATION OF NEST TEMPERATURE ON NESTLING GROWTH AND THERMOREGULATION}

Surprisingly few studies have experimentally manipulated nest temperature after hatching, and those that have done so were all conducted at relatively high latitudes. Rodríguez and Barba (2016a,b) found that both increased and decreased nest temperature had negative effects on the growth of great tit (Parus major) nestlings in a Mediterranean habitat and that heated nestlings suffered reduced post-fledging 
survival (Rodríguez et al., 2016). This suggests that natural nest temperature was close to optimal for nestling development. In contrast, Dawson et al. (2005) found that moderate heating of tree swallow (Tachycineta bicolor) nests increased both nestling growth and fledging success in a northern, temperate area. These studies did not record changes in nestling body temperature or any other metabolic responses to the manipulation. Thus, we do not know if the effects of changing temperature can be explained by alteration of the ontogeny of thermoregulation in the nestlings. Andreasson et al. (2018) heated blue tit (Cyanistes caeruleus) nests and measured both nestling growth and thermoregulatory responses to the manipulation. These authors found that nestlings in heated nests had a higher body temperature and lower body mass gain throughout the nestling period. Body temperature was high and stable in the heated group even at developmental stages where the control birds were poikilothermic. Hence, it is conceivable that the suppressing effects on growth were, at least partly, explained by increased allocation of resources to thermoregulation. Yet, Andreasson et al. (2018) found no effects on mortality in the nest and, surprisingly, reported slightly higher apparent long-term survival in heated nestlings.

\section{EFFECTS OF TEMPERATURE ON PARENTAL FORAGING AND EFFORT}

In already hot and dry environments, high air temperatures commonly result in reduced foraging rate, mostly due to increased resting during the hottest parts of the day (Tieleman and Williams, 2002; Edwards et al., 2015; Funghi et al., 2019). In addition, foraging success also declines with increasing air temperature, either due to difficulties in combining foraging with behaviors promoting heat dissipation (du Plessis et al., 2012) or due to reduced food availability when prey seek shelter from high temperatures (Cunningham et al., 2013). Hence, nestlings will be fed less, and with lower quality prey, when temperatures increases (Cunningham et al., 2013; Wiley and Ridley, 2016), resulting in costs to growth (Cunningham et al., 2013). It follows that continuing climate change may exacerbate current constraints on foraging to a point where the distribution of bird species in hot and arid areas will be severely restricted, not only due to lethal effects of overheating but also due to missed opportunities that could otherwise have been used for reproduction (Conradie et al., 2019). This could explain why some desert birds with long potential breeding seasons increasingly avoid breeding during the hottest parts of the year (Duursma et al., 2017). Cooperative breeding is commonly observed in such biomes, which is typically interpreted as a mechanism to ameliorate the effects of challenging and unpredictable environments (Rubenstein and Lovette, 2007). It follows that increasingly challenging thermal environments might trigger changes to the size and genetic makeup of cooperative breeder groups as a means of minimizing negative effects on nestlings. However, although high mean daily maximum temperatures reduced nestling survival in southern pied babblers (Turdoides bicolor), larger group sizes of feeding adults could not buffer this effect (Bourne et al., 2020a).
We argue that constraints on foraging success and provisioning rate due to high air temperature are not just confined to hot and arid areas, since, just as in hot environments (Nilsson et al., 2016), adults in temperate areas show increasing body temperature at higher air temperature (Nilsson and Nord, 2018). On top of this, experimental work has shown that body temperature increases with increasing parental effort, resulting in heat storage (Nilsson and Nord, 2018). If parents cannot dissipate this excess heat at the same rate as it is produced, they may reach a point where they have to reduce work rate to avoid the deleterious consequences of sustained hyperthermia (Speakman and Król, 2010). For example, breeding starlings (Sturnus vulgaris) reduce provisioning rate when air temperature increase, probably due to increased heat load (Clark, 1987). It follows that the risk of hyperthermia due to increased heat load may shift the diurnal pattern of nestling feeding. By concentrating feeding to cooler times of the day, i.e., dusk and dawn, the risk of hyperthermia might be minimized given that nestlings can sustain the resultant longer periods of low provisioning rates. The risk of overheating may also affect birds during other parts of the annual cycle. Eider ducks (Somateria mollissima) in the Baltic Sea stop flying altogether when reaching a heat storage threshold (Guillemette et al., 2016).

\section{EVALUATING THE CAUSAL ROLE OF TEMPERATURE ON PARENTAL EFFORT}

While it is difficult to manipulate air temperature in natural environments, some studies have increased parents' ability for heat dissipation by removing the feathers covering the ventral parts of the body to create a thermal window. After experimental facilitation of heat dissipation, nestling-feeding blue tits in northern Europe could maintain work rate whilst simultaneously reducing body temperature, investing more in self-maintenance, and siring larger nestlings (Nord and Nilsson, 2019). Featherclipped female tree swallows at a temperate site in North America had higher feeding rates (at least in hot air temperatures) and produced heavier nestlings compared to controls (Tapper et al., 2020). This underlines that effects of high temperatures are likely also in temperate areas. However, the effect of a release from the risk of overheating may be context-dependent. For example, in another study on blue tits, breeding females used the reduced constraints on foraging effort to invest in selfmaintenance by increasing their level of constitutive innate immunity (Andreasson et al., 2020).

\section{THE LINK BETWEEN TEMPERATURE, PARENTAL EFFORT AND NESTLING PHENOTYPE}

Reduced and variable provisioning rates in higher-than-normal temperatures may put nestlings into periods of food stress. This can cause irreversible effects on the subsequent adult phenotype (e.g., Monaghan, 2008). For example, zebra finch (Taeniopygia guttata) nestlings reared under food restriction had higher intake 
rates and basal metabolic rate in adulthood than nestlings reared with ad libitum food (Careau et al., 2014). Furthermore, zebra finch nestlings in the wild fledged at smaller size in warmer than in somewhat cooler areas (Andrew et al., 2017). This size difference remained when zebra finches were reared in captivity with ad libitum food (Andrew et al., 2017). This indicates that body size changes may be a result of either thermal adaptation to reduce heat load, or a direct suppressing effect of heat on nestling growth (Andreasson et al., 2018), more than a consequence of altered parental behavior per se (Wiley and Ridley, 2016). Thus, increasing temperatures during nestling development can drive changes in physiological and morphological traits that remain to adulthood in both direct and indirect ways (see also Nord and Giroud, 2020).

\section{FUTURE PERSPECTIVES}

The few studies on heat constraints on avian reproduction that are available from colder parts of the world suggest that, just as in hot and dry areas, higher-than-normal temperature can suppress current and future reproduction in both direct and indirect ways. However, most causal aspects of thermal constraints on parental effort and chick development remain largely unexplored. It will be particularly important to separate the causal role of temperature on adult and juvenile traits from any associated, indirect, effect of temperature on the ecosystem. Below, we outline what we believe to be the most critical areas for future investigation and experimentation, with the hope of catalyzing further and broader study within this timely research field.

(i) Broader geographic and environmental coverage: Previous studies suggest variation in effects of heat exposure depending on the thermal context of the habitat. There is now a need to broaden the latitudinal and altitudinal coverage to better understand when increasing temperature is ameliorating and when it is constraining. Studies should also assess when, within a site, a given temperature change transitions from being beneficial to detrimental, and how this varies across a species' range, which could indicate potential for local adaptation.

(ii) Experimental studies: With few exceptions, studies that have investigated the thermal sensitivity of bird reproduction have used natural variation in air or nest temperature, which limits conclusions on causality. We need more studies that manipulate the thermal environmental or heat transfer processes in parents and/or chicks in fully factorial designs within and beyond predictions from climate change models in both cold and warm locations (e.g., IPCC, 2013; Figure 1). This will inform us about the extent to which climate change and extreme weather events may impact life history trade-offs. Likewise, there is a need for studies that heat-challenge parents in the wild, because the current approach of relieving constraints need not be ideal to reveal reproductive trade-offs, since: (1) the experimental effect is opposite to that experienced during a heat wave and (2) parents may re-allocate saved resources through different pathways depending on individual demands (e.g., Andreasson et al., 2020). Possible avenues for achieving this could include increased flight costs, changes to lipid content/composition of the skin or other changes to body insulation to alter thermal conductivity, and pharmaceutical treatment to induce peripheral vasoconstriction with consequent reduction in dry- and respiratory heat loss. These methods are not without problems since they inevitably will influence other physiological processes and/or aerodynamic performance of the bird.

(iii) A physiological perspective on behavior: Studies addressing the constraining role of air temperature on avian reproduction would gain from increasingly incorporating thermo-physiological measurement. Because temperatureeffects on nestling development and physiology can be expected to be quadratic, with adverse effects occurring at the warm and cold end of the spectra, such measurements will provide crucial mechanistic depth to observed fitness consequences, such as why heat stress during development sometimes improve short- or long-term survival (Dawson et al., 2005; Andreasson et al., 2018) but at other times negatively affect survival (Rodríguez et al., 2016).

(iv) Studies across life histories: It is conceivable that species with different life histories, e.g., slow- or fast-paces of life or resident vs. migratory behavior, will be differentially affected by temperature change. For example, species with lower work rate, long lifespan and small brood sizes may be better equipped to deal with heat waves, e.g., by reducing reproductive effort during heat wave years (cf. Martin and Mouton, 2020). Moreover, most birds at high latitudes are migrants (Newton and Dale, 1996). At least in some cases, such birds have not advanced the start of reproduction to match warming springs when resident, sympatrically breeding, species have (e.g., Källander et al., 2017). Thus, there may be selection for residency, increasing the proportion of residents in partially migratory birds. In addition, it remains to be tested if the decreased activity during the hottest part of the day, commonly observed in warm and dry areas (Tieleman and Williams, 2002; Edwards et al., 2015; Funghi et al., 2019), will become more pronounced with increasing temperatures globally, and more common overall in temperate biomes.

(v) Short- and long-term effects on the individual: In some cases, a high temperature during breeding is conducive for growth and survival (Dawson et al., 2005). In other cases, higher temperature appears constraining in the short term, but beneficial for fitness over longer time periods (Andreasson et al., 2018). In other cases still, it may be the other way around (Nord and Nilsson, 2016). Future studies should monitor fitness effects of temperature over the life span of an individual, and ideally couple this to measurements of physiological mediators of the observed effects.

(vi) Population-level effects: Reports on temperature-driven breeding failure (e.g., Sharpe et al., 2019) or altogether 

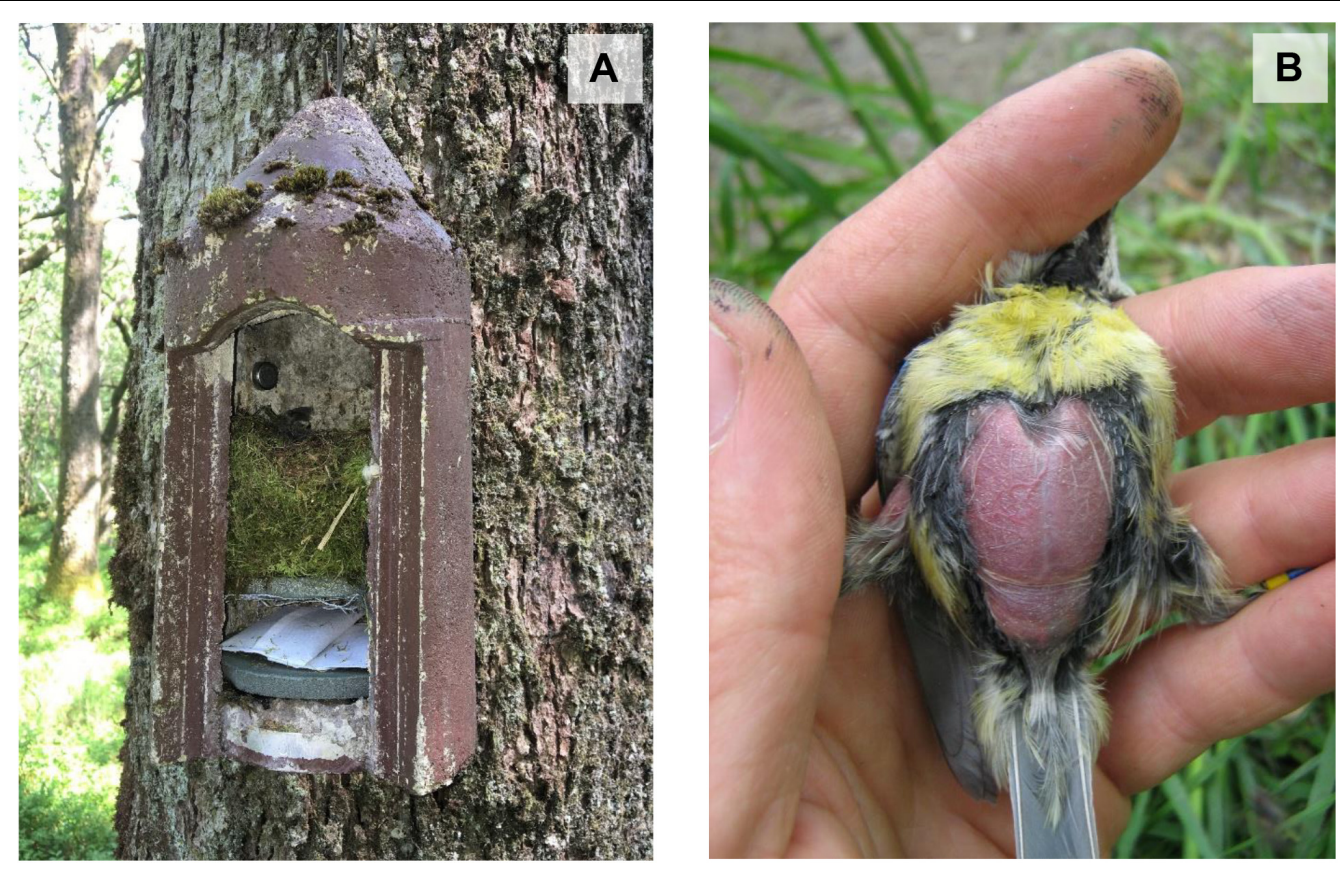

FIGURE 1 | Putative designs for manipulation of heat transfer in nestlings and adults. There is a need for more experimental studies to address the causality of temperature effects on avian reproduction in a warming world. (A) The thermal environment of the nest, at least for hole-nesting species, can easily be manipulated by the addition of a chemical (e.g., hand warmers, as in the figure) or an electrical heating device below the nest. (B) Parental heat transfer can be manipulated by removal of the plumage covering the abdomen and pectoral muscles (the main heat-producing tissue) using small scissors. Future studies should also seek to device methods to decrease heat transfer rate in parents. Photographs @ Jennifer Page [University of Glasgow; Panel (A)], Andreas Nord (B).

skipped breeding seasons (e.g., Duursma et al., 2017; see also Martin and Mouton (2020) for similar effects in relation to drought periods) are becoming increasingly frequent. If this occurs in short-lived species that are unlikely to reproduce more than once, or if coupled to mass mortality events (McKechnie and Wolf, 2010; Riddell et al., 2019), population-level effects are expected. It would be interesting to know e.g., how selection for temperature tolerance operates and manifests under such circumstances (cf. Burggren, 2018; Stillman, 2019), and whether there is compensatory breeding in long-lived species in the breeding season following an extreme weather event (sensu Bourne et al., 2020b) also in temperate areas.

(vii) Heritability of temperature-induced effects: Studies on wild and domesticated animals show that key thermoregulatory traits, such as heat production, body temperature, and temperature tolerance, show moderate to high heritability (typically 0.4-0.6) (e.g., Bowen and Washburn, 1984; Ueno and Komiyama, 1987; Nilsson et al., 2009). It is relevant to ask if induced non-genetic changes to the thermoregulatory phenotype are also inherited. For example, if offspring to parents that developed during, or later experienced, a heat wave are born "heat tolerant," they might be maladapted to the normally colder temperatures of their habitat. Work on ectotherms (e.g., Wang et al., 2015) and plants (e.g., Li and Brawley, 2003) show that parents exposed to warm temperature sire offspring that are more heat-tolerant. To the best of our knowledge, there are no corresponding data for endotherms.

\section{CONCLUSION}

It is clear that increasing global temperature and frequency of extreme weather events may reduce work rate with consequences for parental effort in both warm and, notably, also in temperate environments. This can add to direct, negative effects of high temperature on juvenile growth and maturation (Nord and Giroud, 2020). In hot environments, these factors may result in a shift in the timing of breeding (Duursma et al., 2017), or even aborted breeding (e.g., Sharpe et al., 2019), ultimately causing a shift in distribution ranges (Conradie et al., 2019). In temperate areas, the consequence of reduced work rates may be smaller brood sizes and general changes of life history strategies (Nilsson and Nord, 2018).

Future adaptations to a warmer climate at temperate latitudes may parallel extant adaptations to hot environments, e.g., reduced metabolic rates (Wiersma et al., 2007a,b) to reduce baseline heat production, and reduced reproductive investment (Cardillo, 2002; Wiley and Ridley, 2016) to reduce work rate (and, hence, the amount of activity-generated heat). We also speculate that temperate species may shift their main activity to cooler times of the day, as is known for hard-working, breeding rodents (van der Vinne et al., 2014). Such small mammals have been predicted to become increasingly nocturnal in a warmer world 
(Bonebrake et al., 2020). This is already the strategy chosen by most bats, possibly to avoid adding solar heating to an already heat-generating life style (Speakman et al., 1994). It is unlikely that presently diurnal birds will evolve a nocturnal way of life on account of constraints on foraging in the dark. However, in the future, a greater part of the active foraging time may be allocated to dusk and dawn with a consequent potential increase in mortality by aerial predators.

\section{DATA AVAILABILITY STATEMENT}

The original contributions presented in the study are included in the article.

\section{REFERENCES}

Andreasson, F., Hegemann, A., Nord, A., and Nilsson, J.-Å. (2020). Experimental facilitation of heat loss affects work rate and innate immune function in a breeding passerine bird. J. Exp. Biol. 223:jeb219790. doi: 10.1242/jeb.219790

Andreasson, F., Nord, A., and Nilsson, J.-Å. (2018). Experimentally increased nest temperature affects body temperature, growth and apparent survival in blue tit nestlings. J. Avian Biol. 49:e01620.

Andrew, S., Hurley, L., Mariette, M., and Griffith, S. (2017). Higher temperatures during development reduce body size in the zebra finch in the laboratory and in the wild. J. Evol. Biol. 30, 2156-2164. doi: 10.1111/jeb.13181

Ardia, D. R. (2013). The effects of nestbox thermal environment on fledging success and haematocrit in tree swallows. Avian Biol. Res. 6, 99-103. doi: 10.3184/ $175815513 \times 13609528031394$

Bonebrake, T. C., Rezende, E. L., and Bozinovic, F. (2020). Climate change and thermoregulatory consequences of activity time in mammals. Am. Nat. 196, 45-56. doi: 10.1086/709010

Bourne, A. R., Cunningham, S. J., Spottiswoode, C. N., and Ridley, A. R. (2020a). High temperatures drive offspring mortality in a cooperatively breeding bird. Proc. R. Soc. B 287:20201140. doi: 10.1098/rspb.2020.1140

Bourne, A. R., Cunningham, S. J., Spottiswoode, C. N., and Ridley, A. R. (2020b). Compensatory breeding in years following drought in a desert-dwelling cooperative breeder. Front. Ecol. Evol. 8:190. doi: 10.3389/fevo.2020.00190

Bowen, S. J., and Washburn, K. W. (1984). Genetics of heat tolerance in japanese quail. Poult. Sci. 63, 430-435. doi: 10.3382/ps.0630430

Burggren, W. (2018). Developmental phenotypic plasticity helps bridge stochastic weather events associated with climate change. J. Exp. Biol. 221:jeb161984. doi: $10.1242 /$ jeb.161984

Cardillo, M. (2002). The life-history basis of latitudinal diversity gradients: how do species traits vary from the poles to the equator? J. Anim. Ecol. 71, 79-87. doi: 10.1046/j.0021-8790.2001.00577.x

Careau, V., Buttemer, W. A., and Buchanan, K. L. (2014). Early developmental stress, repeatability, and canalization in a suite of physiological and behavioral traits in female zebra finches. Integr. Comp. Biol. 54, 539-554. doi: 10.1093/icb/ icu095

Charmantier, A., McCleery, R. H., Cole, L. R., Perrins, C., Kruuk, L. E. B., and Sheldon, B. C. (2008). Adaptive phenotypic plasticity in response to climate change in a wild bird population. Science 320, 800-803. doi: 10.1126/science. 1157174

Clark, L. (1987). Thermal constraints on foraging in adult european starlings. Oecologia 71, 233-238. doi: 10.1007/bf00377289

Conradie, S. R., Woodborne, S. M., Cunningham, S. J., and McKechnie, A. E. (2019). Chronic, sublethal effects of high temperatures will cause severe declines in southern African aridzone birds during the 21st century. Proc. Natl. Acad. Sci. U.S.A. 116, 14065-14070. doi: 10.1073/pnas.1821312116

Conradie, S. R., Woodborne, S. M., Wolf, B. O., Pessato, A., Mariette, M. M., and McKechnie, A. E. (2020). Avian mortality risk during heat waves will increase greatly in arid Australia during the 21st century. Conserv. Physiol. 8:coaa048.

\section{AUTHOR CONTRIBUTIONS}

AN conceived the idea. All authors devised the structure of the manuscript, wrote and edited the manuscript, approved the final version, and agreed to be accountable for all contents.

\section{FUNDING}

AN was supported by the Birgit and Hellmuth Hertz Foundation/The Royal Physiographic Society of Lund (grant no. 2017-39034). J-ÅN was supported by a grant from the Swedish Research Council (grant no. 2016-04240). Financial support for the publication charges was provided by the Lund University APC Fund.

Coumou, D., and Robinson, A. (2013). Historic and future increase in the global land area affected by monthly heat extremes. Environ. Res. Lett. 8:034018. doi: 10.1088/1748-9326/8/3/034018

Crick, H. Q. P., Dudley, C., Glue, D. E., and Thomson, D. L. (1997). UK birds are laying eggs earlier. Nature 388:526. doi: 10.1038/41453

Cunningham, S. J., Martin, R. O., Hojem, C. L., and Hockey, P. A. R. (2013). Temperatures in excess of critical thresholds threaten nestling growth and survival in a rapidly-warming arid savanna: a study of common fiscals. PLoS One 8:e74613. doi: 10.1371/journal.pone.0074613

Daniel, R. M., Peterson, M. E., Danson, M. J., Price, N. C., Kelly, S. M., Monk, C. R., et al. (2010). The molecular basis of the effect of temperature on enzyme activity. Biochem. J. 425, 353-360. doi: 10.1042/bj20091254

Dawson, R. D., Lawrie, C. C., and O’Brien, E. L. (2005). The importance of microclimate variation in determining size, growth and survival of avian offspring: experimental evidence from a cavity nesting passerine. Oecologia 144, 499-507. doi: 10.1007/s00442-005-0075-7

Del Vesco, A. P., Gasparino, E., Grieser, D. O., Zancanela, V., Voltolini, D. M., Khatlab, A. S., et al. (2015). Effects of methionine supplementation on the expression of protein deposition-related genes in acute heat stressexposed broilers. PLoS One 10:e0115821. doi: 10.1371/journal.pone.011 5821

du Plessis, K. L., Martin, R. O., Hockey, P. A. R., Cunningham, S. J., and Ridley, A. R. (2012). The costs of keeping cool in a warming world: implications of high temperatures for foraging, thermoregulation and body condition of an aridzone bird. Glob. Change Biol. 18, 3063-3070. doi: 10.1111/j.1365-2486.2012. 02778.x

Dunn, P. O., and Winkler, D. W. (1999). Climate change has affected the breeding date of tree swallows throughout North America. Proc. R. Soc. B 266, $2487-$ 2490. doi: 10.1098/rspb.1999.0950

Duursma, D. E., Gallagher, R. V., and Griffith, S. C. (2017). Characterizing opportunistic breeding at a continental scale using all available sources of phenological data: an assessment of 337 species across the Australian continent. Auk 134, 509-519. doi: 10.1642/auk-16-243.1

Edwards, E. K., Mitchell, N. J., and Ridley, A. R. (2015). The impact of high temperatures on foraging behaviour and body condition in the Western Australian Magpie Cracticus tibicen dorsalis. Ostrich 86, 137-144. doi: 10.2989/ 00306525.2015.1034219

Eeva, T., Lehikoinen, E., Rönkä, M., Lummaa, V., and Currie, D. (2002). Different responses to cold weather in two pied flycatcher populations. Ecography 25, 705-713. doi: 10.1034/j.1600-0587.2002.250606.x

Fey, S. B., Siepielski, A. M., Nusslé, S., Cervantes-Yoshida, K., Hwan, J. L., Huber, E. R., et al. (2015). Recent shifts in the occurrence, cause, and magnitude of animal mass mortality events. Proc. Natl. Acad. Sci. U.S.A. 112, 1083-1088. doi: 10.1073/pnas.1414894112

Funghi, C., McCowan, L. S. C., Schuett, W., and Griffiith, S. C. (2019). High air temperatures induce temporal, spatial and social changes in the foraging behaviour of wild zebra finches. Anim. Behav. 149, 33-43. doi: 10.1016/j. anbehav.2019.01.004 
Gerson, A. R., McKechnie, A. E., Smit, B., Whitfield, M. C., Smith, E. K., Talbot, W. A., et al. (2019). The functional significance of facultative hyperthermia varies with body size and phylogeny in birds. Funct. Ecol. 33, 597-607. doi: 10.1111/1365-2435.13274

Greño, J. L., Belda, E. J., and Barba, E. (2008). Influence of temperatures during the nestling period on post-fledging survival of great tit Parus major in a Mediterranean habitat. J. Avian Biol. 39, 41-49. doi: 10.1111/j.0908-8857.2008. 04120.x

Guillemette, M., Woakes, A. J., Larochelle, J., Polymeropoulos, E. T., Granbois, J.M., Butler, P. J., et al. (2016). Does hyperthermia constrain flight duration in a short-distance migrant? Philos. Trans. R. Soc. B 371, 20150386. doi: 10.1098/ rstb.2015.0386

IPCC (2013). Climate Change 2013: The Physical Science Basis. New York, NY: Oxford University Press.

Källander, H., Hasselquist, D., Hedenström, A., Nord, A., Smith, H. G., and Nilsson, J.-A. (2017). Variation in laying date in relation to spring temperature in three species of tits (Paridae) and pied flycatchers Ficedula hypoleuca in southernmost Sweden. J. Avian Biol. 48, 83-90. doi: 10.1111/jav.01287

Larson, E. R., Eastwood, J. R., Buchanan, K. L., Bennett, A. T. D., and Berg, M. L. (2015). How does nest-box temperature affect nestling growth rate and breeding success in a parrot? Emu 115, 247-255. doi: 10.1071/mu14081

Li, R., and Brawley, S. H. (2003). Improved survival under heat stress in intertidal embryos (Fucus spp.) simultaneously exposed to hypersalinity and the effect of parental thermal history. Mar. Biol. 144, 205-213. doi: 10.1007/s00227-0031190-9

Lin, H., Decuypere, E., and Buyse, J. (2006). Acute heat stress induces oxidative stress in broiler chickens. Comp. Biochem. Physiol. A 144, 11-17. doi: 10.1016/ j.cbpa.2006.01.032

Lloyd, J. D., and Martin, T. E. (2004). Nest-site preference and maternal effects on offspring growth. Behav. Ecol. 15, 816-823. doi: 10.1093/beheco/arh085

Loyau, T., Bedrani, L., Berri, C., Métayer-Coustard, S., Praud, C., Coustham, V., et al. (2015). Cyclic variations in incubation conditions induce adaptive responses to later heat exposure in chickens: a review. Animal 9, 76-85. doi: $10.1017 /$ s1751731114001931

Martin, T. E., and Mouton, J. C. (2020). Longer-lived tropical songbirds reduce breeding activity as they buffer impacts of drought. Nat. Clim. Chang. 10, 953-958. doi: 10.1038/s41558-020-0864-3

McCarty, J. P., and Winkler, D. W. (1999). Relative importance of environmental variables in determining the growth of nestling tree swallows Tachycineta bicolor. Ibis 141, 286-296. doi: 10.1111/j.1474-919x.1999.tb07551.x

McKechnie, A. E., Gerson, A. R., McWhorter, T. J., Smith, E. K., Talbot, W. A., and Wolf, B. O. (2017). Avian thermoregulation in the heat: evaporative cooling in five Australian passerines reveals within-order biogeographic variation in heat tolerance. J. Exp. Biol. 220, 2436-2444. doi: 10.1242/jeb.155507

McKechnie, A. E., Hockey, P. A. R., and Wolf, B. O. (2012). Feeling the heat: Australian landbirds and climate change. Emu 112, i-vii.

McKechnie, A. E., Whitfield, M. C., Smit, B., Gerson, A. R., Smith, E. K., Talbot, W. A., et al. (2016). Avian thermoregulation in the heat: efficient evaporative cooling allows for extreme heat tolerance in four southern Hemisphere columbids. J. Exp. Biol. 219, 2145-2155. doi: 10.1242/jeb.138776

McKechnie, A. E., and Wolf, B. O. (2010). Climate change increases the likelihood of catastrophic avian mortality events during extreme heat waves. Biol. Lett. 6, 253-256. doi: 10.1098/rsbl.2009.0702

Monaghan, P. (2008). Early growth conditions, phenotypic development and environmental change. Philos. Trans. R. Soc. B 363, 1635-1645. doi: 10.1098/ rstb.2007.0011

Murphy, M. T. (1985). Nestling eastern kingbird growth: effects of initial size and ambient temperature. Ecology 66, 162-170. doi: 10.2307/1941316

Mutiibwa, D., Vavrus, S. J., McAfee, S. A., and Albright, T. P. (2015). Recent spatiotemporal patterns in temperature extremes across conterminous United States. J. Geophys. Res. Atmos. 120, 7378-7392. doi: 10.1002/ 2015jd023598

Naga Raja Kumari, K., and Narendra Nath, D. (2018). Ameliorative measures to counter heat stress in poultry. Worlds Poult. Sci. J. 74, 117-130. doi: 10.1017/ s0043933917001003

Newton, I., and Dale, L. C. (1996). Bird migration at different latitudes in eastern North America. Auk 113, 626-635. doi: 10.2307/4088983
Nilsson, J.-Å., Åkesson, M., and Nilsson, J. F. (2009). Heritability of resting metabolic rate in a wild population of blue tits. J. Evol. Biol. 22, 1867-1874. doi: 10.1111/j.1420-9101.2009.01798.x

Nilsson, J.-Å., Molokwu, M. N., and Olsson, O. (2016). Body temperature regulation in hot environments. PLoS One 11:e0161481. doi: 10.1371/journal. pone. 0161481

Nilsson, J.-A., and Nord, A. (2018). Testing the heat dissipation limit theory in a breeding passerine. Proc. R. Soc. B 285:20180652. doi: 10.1098/rspb.2018.0652

Nord, A., and Giroud, S. (2020). Lifelong effects of thermal challenges during development in birds and mammals. Front. Physiol. 11:419.

Nord, A., and Nilsson, J.-Å. (2016). Long-term consequences of high incubation temperature in a wild bird population. Biol. Lett. 12:20160087. doi: 10.1098/ rsbl.2016.0087

Nord, A., and Nilsson, J.- $\AA$. (2019). Heat dissipation rate constrains reproductive investment in a wild bird. Funct. Ecol. 33, 250-259. doi: 10.1111/1365-2435. 13243

O’Connor, R. S., Wolf, B. O., Brigham, R. M., and McKechnie, A. E. (2017). Avian thermoregulation in the heat: efficient evaporative cooling in two southern African nightjars. J. Comp. Physiol. B 187, 477-491. doi: 10.1007/s00360-0161047-4

Pattinson, N. B., Thompson, M. L., Griego, M., Russell, G., Mitchell, N. J., Martin, R. O., et al. (2020). Heat dissipation behaviour of birds in seasonally hot arid-zones: are there global patterns? J. Avian Biol. 51:e02350.

Riddell, E. A., Iknayan, K. J., Wolf, O. B., Sinervo, B., and Bessinger, S. R. (2019). Cooling requirements fueled the collapse of a desert bird community from climate change. Proc. Natl. Acad. Sci. U.S.A. 116:201908791.

Rodríguez, S., and Barba, E. (2016a). Effects of cool nest microclimates on nestling development: an experimental study with Mediterranean great tits Parus major. Ardeola 63, 251-260. doi: 10.13157/arla.63.2.2016.ra2

Rodríguez, S., and Barba, E. (2016b). Nestling growth is impaired by heat stress: an experimental study in a Mediterranean great tit population. Zool. Stud. 55:40.

Rodríguez, S., Diez-Méndez, D., and Barba, E. (2016). Negative effects of high temperatures during development on immediate post-fledging survival in great tits Parus major. Acta Ornithol. 51, 235-244. doi: 10.3161/00016454ao2016.51. 2.009

Rubenstein, D. R., and Lovette, I. J. (2007). Temporal environmental variability drives the evolution of cooperative breeding in birds. Curr. Biol. 21, $72-78$.

Salaberria, C., Celis, P., López-Rull, I., and Gil, D. (2014). Effects of temperature and nest heat exposure on nestling growth, dehydration and survival in a Mediterranean hole-nesting passerine. Ibis 156, 265-275. doi: 10.1111/ibi. 12121

Sanz, J. J. (2002). Climate change and breeding parameters of great and blue tits throughout the western Palaearctic. Glob. Change Biol. 8, 409-422. doi: 10.1046/j.1365-2486.2002.00496.x

Sharpe, L., Cale, B., and Gardner, J. L. (2019). Weighing the cost: the impact of serial heatwaves on body mass in a small Australian passerine. J. Avian Biol. 50:e02355.

Smit, B., Zietsman, G., Martin, R. O., Cunningham, S. J., McKechnie, A. E., and Hockey, P. A. R. (2016). Behavioural responses to heat in desert birds: implications for predicting vulnerability to climate warming. Clim. Chang. Responses 3:9.

Smith, E. K., O’Neill, J., Gerson, A. R., and Wolf, B. O. (2015). Avian thermoregulation in the heat: resting metabolism, evaporative cooling and heat tolerance in Sonoran Desert doves and quail. J. Exp. Biol. 218, 3636-3646. doi: $10.1242 /$ jeb. 128645

Smith, E. K., O’Neill, J. J., Gerson, A. R., McKechnie, A. E., and Wolf, B. O. (2017). Avian thermoregulation in the heat: resting metabolism, evaporative cooling and heat tolerance in Sonoran Desert songbirds. J. Exp. Biol. 220, 3290-3300. doi: 10.1242/jeb.161141

Speakman, J. R., Hays, C. G., and Webb, P. I. (1994). Is hyperthermia a constraint on the diurnal activity of bats? J. Theor. Biol. 171, 325-341. doi: 10.1006/jtbi. 1994.1235

Speakman, J. R., and Król, E. (2010). Maximal heat dissipation capacity and hyperthermia risk: neglected key factors in the ecology of endotherms. J. Anim. Ecol. 79, 726-746. 
Stillman, J. H. (2019). Heat waves, the new normal: summertime temperature extremes will impact animals, ecosystems, and human communities. Physiology 34, 86-100. doi: 10.1152/physiol.00040.2018

Talbot, W. A., McWhorter, T. J., Gerson, A. R., McKechnie, A. E., and Wolf, B. O. (2017). Avian thermoregulation in the heat: evaporative cooling capacity of aridzone Caprimulgiformes from two continents. J. Exp. Biol. 220, 3488-3498. doi: $10.1242 /$ jeb. 161653

Tapper, S., Nocera, J. J., and Burness, G. (2020). Heat dissipation capacity influences reproductive performance in an aerial insectivore. J. Exp. Biol. 223:jeb222232. doi: $10.1242 /$ jeb. 222232

Tieleman, B. I., and Williams, J. B. (2002). Effects of food supplementation on behavioural decisions of hoopoe-larks in the Arabian Desert: balancing water, energy and thermoregulation. Anim. Behav. 63, 519-529. doi: 10.1006/anbe. 2001.1927

Ueno, T., and Komiyama, T. (1987). Genetic variation in tolerance to extreme thermal environments in white leghorn chickens. Jpn. Poult. Sci. 24, 1-7. doi: 10.2141/jpsa.24.1

van de Ven, T. M. F. N., McKechnie, A. E., Er, S., and Cunningham, S. J. (2020). High temperatures are associated with substantial reductions in breeding success and offspring quality in an arid-zone bird. Oecologia 193, 225-235. doi: 10.1007/s00442-020-04644-6

van der Vinne, V., Simons, M. J., Reimert, I., and Gerkema, M. P. (2014). Temporal niche switching and reduced nest attendance in response to heat dissipation limits in lactating common voles (Microtus arvalis). Physiol. Behav. 128, 295302. doi: 10.1016/j.physbeh.2014.01.019

Visser, M. E., Van Noordwijk, A. J., Tinbergen, J. M., and Lessells, C. M. (1998). Warmer springs lead to mistimed reproduction in great tits (Parus major). Proc. R. Soc. B 265, 1867-1870. doi: 10.1098/rspb.1998. 0514
Wang, Q.-L., Yu, S.-S., and Dong, Y.-W. (2015). Parental effect of long acclimatization on thermal tolerance of juvenile sea cucumber Apostichopus japonicas. PLoS One 10:e0143372. doi: 10.1371/journal.pone.0143372

Whitfield, M. C., Smit, B., McKechnie, A. E., and Wolf, B. O. (2015). Avian thermoregulation in the heat: scaling of heat tolerance and evaporative cooling capacity in three southern African arid-zone passerines. J. Exp. Biol. 218, 1705-1714. doi: 10.1242/jeb.121749

Wiersma, P., Chappell, M. A., and Williams, J. B. (2007a). Cold-and exerciseinduced peak metabolic rates in tropical birds. Proc. Natl. Acad. Sci. U.S.A. 104, 20866-20871. doi: 10.1073/pnas.0707683104

Wiersma, P., Muñoz-Garcia, A., Walker, A., and Williams, J. B. (2007b). Tropical birds have a slow pace of life. Proc. Natl. Acad. Sci. U.S.A. 104, 9340-9345. doi: 10.1073/pnas.0702212104

Wiley, E. M., and Ridley, A. R. (2016). The effects of temperature on offspring provisioning in a cooperative breeder. Anim. Behav. 117, 187-195. doi: 10.1016/ j.anbehav.2016.05.009

Yahav, S. (2009). Alleviating heat stress in domestic fowl: different strategies. Worlds Poult. Sci. J. 65, 719-732. doi: 10.1017/s004393390900049x

Conflict of Interest: The authors declare that the research was conducted in the absence of any commercial or financial relationships that could be construed as a potential conflict of interest.

Copyright (C) 2020 Andreasson, Nilsson and Nord. This is an open-access article distributed under the terms of the Creative Commons Attribution License (CC BY). The use, distribution or reproduction in other forums is permitted, provided the original author(s) and the copyright owner(s) are credited and that the original publication in this journal is cited, in accordance with accepted academic practice. No use, distribution or reproduction is permitted which does not comply with these terms. 